\title{
Effect of sorafenib on des- $\gamma$-carboxyprothrombin secretion by a human hepatocellular carcinoma cell line
}

\author{
SACHIKO OGASAWARA ${ }^{1 *}$, MASAMICHI NAKAYAMA $^{1 *}$, JUN AKIBA $^{2}$, \\ HIRONORI KUSANO ${ }^{1}$ and HIROHISA YANO ${ }^{1}$ \\ ${ }^{1}$ Department of Pathology, Kurume University School of Medicine; ${ }^{2}$ Department of Diagnostic Pathology, \\ Kurume University Hospital, Kurume, Fukuoka 830-0011, Japan
}

Received September 26, 2016; Accepted January 6, 2017

DOI: $10.3892 / \mathrm{ol} .2017 .6451$

\begin{abstract}
Patients with hepatocellular carcinoma (HCC) who respond to sorafenib have been reported to exhibit an increase in the level of des- $\gamma$-carboxyprothrombin (DCP) in the blood, subsequent to the initiation of sorafenib treatment. In the present study, the levels of secretion of DCP and DCP with more $\gamma$-carboxyglutamic residues (NX-DCP) and the effects of hypoxic conditions were examined in 13 liver cancer cell lines, and the presence of vitamin K and sorafenib, in the KYN-2 cell line, which resulted in confirmed DCP and NX-DCP secretion. DCP, NX-DCP and prothrombin secretion were confirmed in $2 / 13$ cell lines, KYN-2 and KIM-1. The level of secretions increased under hypoxic conditions. The addition of vitamin $\mathrm{K}$ suppressed cell proliferation, and DCP expression decreased to below detectable levels, however the level of prothrombin expression increased. Sorafenib treatment increased the level of apoptosis and suppressed cell proliferation, and decreased DCP and NX-DCP. In contrast, levels of prothrombin and vascular endothelial growth factor (VEGF) expression exhibited a slight increase. When the same experiment was conducted under hypoxic conditions, DCP secretion significantly decreased in the presence of sorafenib. The level of DCP secretion increased by several fold in the sorafenib-treated and non-treated cells compared with the normoxic conditions. Prothrombin and VEGF values with normoxic conditions remained almost similar with hypoxic conditions. Under hypoxic conditions, NX-DCP significantly decreased below the control values for the first $48 \mathrm{~h}$ subsequent to sorafenib treatment, but significantly increased at $72 \mathrm{~h}$. In vivo experiments demonstrated that sorafenib inhibited
\end{abstract}

Correspondence to: Dr Sachiko Ogasawara, Department of Pathology, Kurume University School of Medicine, 67 Asahi-machi, Kurume, Fukuoka 830-0011, Japan

E-mail: sachiko@med.kurume-u.ac.jp

*Contributed equally

Key words: hepatocellular carcinoma, des- $\gamma$-carboxyprothrombin, NX-des- $\gamma$-carboxyprothrombin, prothrombin, sorafenib angiogenesis and tumor proliferation, but the levels of DCP and NX-DCP did not differ significantly from the controls. These findings indicate that the suppression of neovascularization by sorafenib promotes blood vessel ischemia, producing hypoxic conditions whereby vitamin $\mathrm{K}$ uptake and utilization efficiency is reduced.

\section{Introduction}

Hepatocellular carcinoma (HCC) is one of the most common types of cancer and the second leading cause of malignant-neoplasm-associated mortality, worldwide (1). However, the molecular targeted therapy, sorafenib, has exhibited promising results in the treatment of patients with advanced HCC (2). Sorafenib is a small molecule that functions as an oral multikinase inhibitor and is also approved for the treatment of advanced renal cell carcinoma (3). Sorafenib exhibits direct antiproliferative effects on tumor cells due to the blockade of numerous intracellular serine/threonine kinases (e.g., C-Raf and B-Raf), and indirect effects due to the blockade of receptor tyrosine kinases, including vascular endothelial growth factor receptors (VEGFRs) and platelet-derived growth factor receptor- $\beta$ (PDGFR- $\beta$ ) on endothelial cells followed by the inhibition of angiogenesis $(1,4,5)$. Des- $\gamma$-carboxyprothrombin (DCP), also known as protein induced by vitamin $\mathrm{K}$ absence or antagonist-II (PIVKA-II), is an abnormal prothrombin routinely used as a tumor marker for $\mathrm{HCC}$, and may be predictive of aggressive tumor behavior and a poor prognosis (6-8). Serum DCP levels also increase in patients with a vitamin $\mathrm{K}$ deficiency, including those taking warfarin or who exhibit obstructive jaundice. The DCP molecules in these conditions were demonstrated to contain more $\gamma$-carboxyglutamic (Gla) residues and was termed NX-DCP. A number of previous studies reported that serum NX-DCP was also useful for the detection of HCC $(6,9)$. We previously revealed that patients with serum NX-DCP-positive HCC exhibited significantly larger tumors, more frequent portal vein invasion and a poorer prognosis (10). The evaluation of $\alpha$-fetoprotein (AFP) level is already used for routine surveillance and noninvasive diagnosis of $\mathrm{HCC}$, and the prediction of prognosis and monitoring of recurrence subsequent to treatment $(11,12)$. As the DCP level is not always correlated with the AFP level, the recommendations in previous studies include combined testing of 
DCP and Lens culinaris agglutinin-reactive fraction of AFP has been established $(13,14)$.

Sorafenib is widely used for patients with advanced HCC. However, at present, there are no clinical parameters to predict sorafenib efficacy. DCP levels were reported to be increased in patients treated with sorafenib (15-17), and the elevation of DCP may indicate a high therapeutic effect of sorafenib $(16,17)$. Although the precise mechanism remains unknown, the ischemic and/or hypoxic conditions of HCC may be associated with the elevation of DCP subsequent to sorafenib treatment. In the present study, the mechanism of DCP level elevation in hypoxic conditions and sorafenib treatment was investigated using the HCC KYN-2 cell line, which produces DCP.

\section{Materials and methods}

Cell lines and cell culture. The present study used 11 HCC cell lines KIM-1, KYN-1, KYN-2, KYN-3, HAK-1A, HAK-1B, HAK-2, HAK-3, HAK-4, HAK-5 and HAK-6, and 2 combined hepatocellular-cholangiocarcinoma (CHC) cell lines, $\mathrm{KMCH}-1$ and $\mathrm{KMCH}-2$. These cell lines were originally established in the Department of Pathology (Kurume University School of Medicine, Kurume, Japan), and each cell line retains the morphological and functional features of the original tumor as described elsewhere (18-26). The cells were grown in Dulbecco's modified Eagle's medium (Nissui, Tokyo, Japan) supplemented with $2.5 \%$ heat-inactivated $\left(56^{\circ} \mathrm{C}, 30 \mathrm{~min}\right)$ fetal bovine serum (FBS; Bioserum, Victoria, Australia), $100 \mathrm{U} / \mathrm{ml}$ penicillin, $100 \mu \mathrm{g} / \mathrm{ml}$ streptomycin (Gibco; Thermo Fisher Scientific, Inc., Waltham, MA, USA) and $12 \mathrm{mmol} / 1$ sodium bicarbonate, in a humidified atmosphere of $5 \% \mathrm{CO}_{2}$ at $37^{\circ} \mathrm{C}$.

Measurement of DCP, NX-DCP and prothrombin levels. The cultured cells were seeded on 6-well plates (Falcon, BD Biosciences Labware, Tokyo, Japan) at a density of $3-10 \times 10^{4}$ cells/well, and cells on the plates were cultured in normoxic or hypoxic, $1 \% \mathrm{O}_{2}$, conditions for 3 days. The prothrombin, DCP and NX-DCP levels in the supernatant (centrifuged for $10 \mathrm{~min}, 12,000 \mathrm{x} \mathrm{g}, 4^{\circ} \mathrm{C}$ ) and cell lysate were determined using an ELISA kit (EIDIA Co., Ltd., Tokyo, Japan) for prothrombin and an electro-chemiluminescence immunoassay (ECLIA) kit (EIDIA Co., Ltd.) for DCP and NX-DCP, according to the protocol of the manufacturer. The polyclonal antibody for prothrombin was sourced from the ELISA kit, the monoclonal antibody for DCP (MU-3) and monoclonal antibodies for NX-DCP (P-11 and P-16) were sourced from the ECLIA kit.

Effects of vitamin $K$ on the secretion of $D C P, N X-D C P$ and prothrombin. KYN-2 cells were seeded on $10 \mathrm{~cm}$ dishes (Falcon, BD Biosciences Labware) at a density of $1.3 \times 10^{5}$ cells/well. The media were replaced the subsequent day with medium alone or medium containing $100 \mathrm{nM}$ vitamin $\mathrm{K}$ (Sigma-Aldrich; Merck Millipore, Darmstadt, Germany) and the cells were cultured in normoxic or hypoxic condition for $72 \mathrm{~h}$. The cell number was then determined and the supernatant was collected (centrifuged for $10 \mathrm{~min}, 12,000 \times \mathrm{g}, 4^{\circ} \mathrm{C}$ ) and used for DCP, NX-DCP and prothrombin measurements by ECLIA and ELISA.
Effect of sorafenib on proliferation and secretion of DCP, $N X-D C P$, prothrombin and VEGF. A total of $5 \times 10^{4}$ cells per well KYN-2 cells were seeded on 6-well plates. The medium was replaced the next day with medium alone or medium containing $1.25 \mu \mathrm{M}$ sorafenib (Cell Signaling Technology, Danvers, MA) and the cells were cultured in normoxic or hypoxic condition for 24,48 , or $72 \mathrm{~h}$. Then the cell number was determined and the supernatant was collected and used for DCP, NX-DCP, prothrombin and vascular endothelial growth factor (VEGF) measurements by ECLIA and ELISA. The supernatant was also obtained from cells cultured with sorafenib $(0.313,0.625$ or $1.25 \mu \mathrm{M})$ for $72 \mathrm{~h}$ and used for the evaluation performed by ECLIA and ELISA.

Effects of sorafenib on tumor proliferation and serum DCP and NX-DCP levels in nude mice. A total of $1 \times 10^{7}$ cells $/ 100 \mu 1$ cultured KYN-2 cells were subcutaneously injected into the backs of 4-week-old female BALB/c nude mice. Following two weeks, the mice were divided into 3 groups of 12 in order to equalize the mean diameter of tumors in each group. Each group was assigned to 1 of the 3 treatment groups: Control; $300 \mu \mathrm{g} / \mathrm{mouse} /$ day sorafenib; $600 \mu \mathrm{g} / \mathrm{mouse} /$ day sorafenib. The $300 \mu \mathrm{g}$ dose of sorafenib in proportion to the average body weight of a mouse, $20 \mathrm{~g}$, was $15 \mathrm{mg} / \mathrm{kg}$, which is comparable to a clinical dose of $800 \mathrm{mg}$ total/day. The sorafenib was diluted with $12.5 \%$ Cremophor EL (Sigma-Aldrich; Merck Millipore)/12.5\% ethanol/75\% water for oral dosing in mice, and was administered by tube feeding once a day. In the control group, $0.2 \mathrm{ml}$ Cremophor EL/ethanol/water $(12.5 / 12.5 / 75)$ alone was administered by tube feeding once a day. Tumor size was measured in two directions using calipers, and tumor volume $\left(\mathrm{mm}^{3}\right)$ was estimated by using the equation: Length $\mathrm{x}$ (width) $)^{2} \times 0.5$. This measurement was performed every 2 or 3 days. On day 4, 9 or 14, subsequent to drawing blood for measuring the serum DCP and NX-DCP level, 4 mice in each group were sacrificed by cervical dislocation and the tumors were resected. The tumor weight was measured.

Immunohistochemical analysis. The resected tumors were fixed in formalin and prepared into paraffin sections, and underwent hematoxylin and eosin staining and immunochemistry. Immunohistochemical staining with monoclonal rat anti-mouse cluster of differentiation (CD)34 (cat. no. ab8185; dilution, 1:50; Abcam, Cambridge, UK) was performed using the standard avidin-biotin-peroxidase complex method and 3,3'-diaminobenzidine solution was used for color development. The microvessel density (MVD) was evaluated within the tumor. To quantify MVD, the slides stained with CD34 were observed at low power field, magnification, x10-100, using a light microscope. A total of 5 areas with high MVD were selected at a high-power field, magnification, x200, and the MVD of these areas in each specimen was measured using the WinROOF software package (version 6.1; Mitani Corporation, Fukui, Japan).

Statistical analysis. Data are expressed as the mean \pm standard deviation. Comparisons between groups were performed using un-paired Student's t-test and two-factor factorial analysis of variance. $\mathrm{P}<0.05$ was considered to indicate a statistically significant difference. 

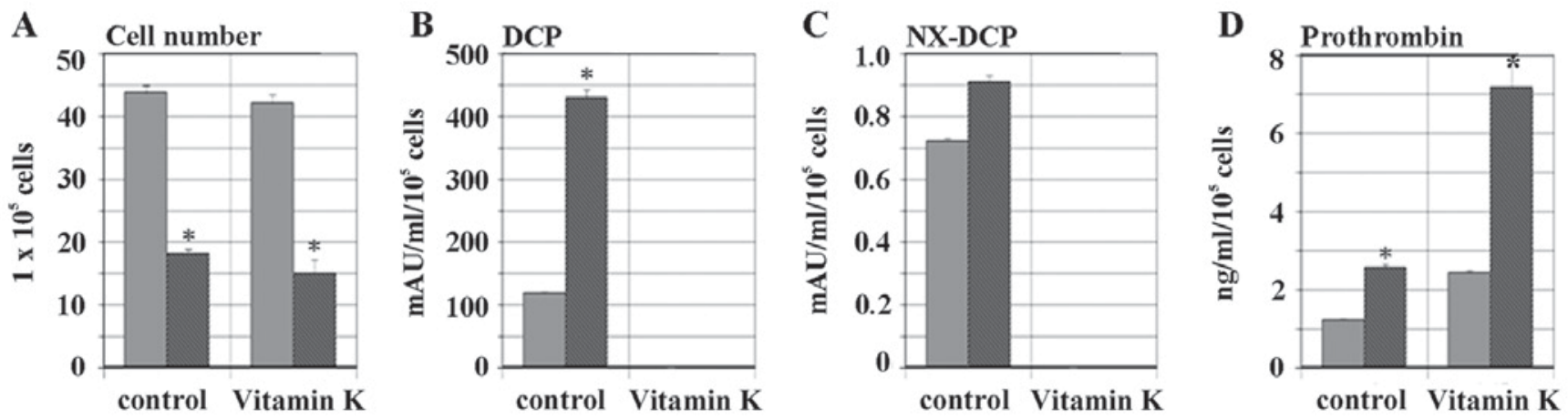

Figure 1. Effects of vitamin K on cell growth, and secretions of DCP, NX-DCP, and prothrombin in normoxic or hypoxic condition. KYN-2 cells were cultured with or without $100 \mathrm{nM}$ vitamin $\mathrm{K}$ for $72 \mathrm{~h}$ in normoxic or hypoxic condition. (A) Viable cell number and levels of (B) DCP, (C) NX-DCP and (D) prothrombin in culture medium in normoxic or hypoxic condition are illustrated. Gray bar, normoxic conditions; black bar, hypoxic conditions. ${ }^{*} \mathrm{P}<0.001$ in normoxic vs. hypoxic conditions. DCP, des- $\gamma$-carboxyprothrombin; NX-DCP, des- $\gamma$-carboxyprothrombin with more $\gamma$-carboxyglutamic residues.

Ethical statement. The present study was approved by the Ethics Committee of Kurume University (approval no. 10007). Animal experiments for this study were approved by the Ethics Review Committee for Animal Experimentation of Kurume University School of Medicine (Kurume, Japan).

\section{Results}

Measurement of DCP, NX-DCP and prothrombin. The levels of DCP secretion in the supernatant of KYN-2 cells under normoxic conditions per $\mu \mathrm{g}$ protein was $11.2 \mathrm{mAU} / \mathrm{ml} / \mu \mathrm{g}$ protein, and the expression in the cell lysate was $165.4 \mathrm{mAU} / \mathrm{ml} / \mu \mathrm{g}$ protein. Under hypoxic conditions, the DCP expression levels were $66.7 \mathrm{mAU} / \mathrm{ml} / \mu \mathrm{g}$ protein in the supernatant, and $80.9 \mathrm{mAU} / \mathrm{ml} / \mu \mathrm{g}$ protein in the cell lysate. In the KIM-1 cells, the level of DCP secretion in the supernatant cultured under normoxic conditions was $0.8 \mathrm{mAU} / \mathrm{ml} / \mu \mathrm{g}$ protein, and the expression in the cell lysate was $126.7 \mathrm{mAU} / \mathrm{ml} / \mu \mathrm{g}$ protein. In hypoxic conditions, the levels of DCP expression were $19.1 \mathrm{mAU} / \mathrm{ml} / \mu \mathrm{g}$ protein in the supernatant and $872.4 \mathrm{mAU} / \mathrm{ml} / \mu \mathrm{g}$ protein in the cell lysate. The levels of NX-DCP secretion in the supernatant of the KYN-2 cells was $0.3 \mathrm{mAU} / \mathrm{ml} / \mu \mathrm{g}$ protein under normoxic conditions, and $0.9 \mathrm{mAU} / \mathrm{ml} / \mu \mathrm{g}$ protein under hypoxic condition. In the KIM-1 cells, the levels of NX-DCP secretion in the supernatant were $0.2 \mathrm{mAU} / \mathrm{ml} / \mu \mathrm{g}$ protein under normoxic conditions, and $0.7 \mathrm{mAU} / \mathrm{ml} / \mu \mathrm{g}$ protein under hypoxic condition. The levels of prothrombin secretion under normoxic conditions were $0.6 \mathrm{mAU} / \mathrm{ml} / \mu \mathrm{g}$ protein in $\mathrm{KYN}-2$ cells, and $0.6 \mathrm{mAU} / \mathrm{ml} / \mu \mathrm{g}$ protein in the KIM-1 cells. Under hypoxic conditions, the levels of prothrombin expression were $0.9 \mathrm{mAU} / \mathrm{ml} / \mu \mathrm{g}$ protein and $0.9 \mathrm{mAU} / \mathrm{ml} / \mu \mathrm{g}$ protein for $\mathrm{KYN}-2$ and $\mathrm{KIM}-1$, respectively. The expression levels of DCP, NX-DCP and prothrombin in all of the other 11 cell lines were less than $0.1 \mathrm{mAU} / \mathrm{ml} / \mu \mathrm{g}$ protein (data not shown).

Effects of vitamin $K$ on secretion of DCP, NX-DCP and prothrombin. The addition of vitamin $\mathrm{K}$ to the culture medium suppressed cell proliferation in the KYN-2 cells under normoxic and hypoxic conditions, as demonstrated in Fig. 1A. The level of secretion of DCP under normoxic condition without the addition of vitamin $\mathrm{K}$ was $118.0 \pm 2.2 \mathrm{mAU} / \mathrm{ml} / 10^{5}$ cells, whereas levels of DCP increased significantly to $428.2 \pm 14.2 \mathrm{mAU} / \mathrm{ml} / 10^{5}$ cells under hypoxic condition $(\mathrm{P}<0.001)$. However, when vitamin $\mathrm{K}$ was added to the cell cultures, the levels DCP secretion decreased below $0.5 \mathrm{mAU} / \mathrm{ml} / 10^{5}$ cells in normoxic and hypoxic condition, as illustrated in Fig. 1B. NX-DCP expression in normoxic and hypoxic conditions was $<1.0 \mathrm{mAU} / \mathrm{ml} / 10^{5}$ cells. NX-DCP expression was not detected with the addition of vitamin $\mathrm{K}$, as demonstrated in Fig. 1C. The levels of prothrombin secretion were $1.2 \pm 0.1 \mathrm{mAU} / \mathrm{ml} / 10^{5}$ cells under normoxic conditions without vitamin $\mathrm{K}$, and increased to $2.6 \pm 0.1 \mathrm{mAU} / \mathrm{ml} / 10^{5}$ cells under hypoxic conditions $(\mathrm{P}<0.001)$. Subsequent to the addition of vitamin $\mathrm{K}$, the prothrombin levels were $2.4 \pm 0.1 \mathrm{mAU} / \mathrm{ml} / 10^{5}$ cells under normoxic conditions, but increased to $7.1 \pm 0.7 \mathrm{mAU} / \mathrm{ml} / 10^{5}$ cells in hypoxic conditions $(\mathrm{P}<0.001)$, as illustrated in Fig. 1D.

Effect of sorafenib on proliferation and secretion of DCP, $N X-D C P$, prothrombin and VEGF. The cells cultured with $1.25 \mu \mathrm{M}$ sorafenib decreased in number to $25 \%$ of the control group on day $3(\mathrm{P}<0.001)$, as demonstrated in Fig. 2A. Sorafenib inhibited the levels of DCP secretion by the HCC cells: The levels of DCP in the culture medium of the control cells at 24,48 and $72 \mathrm{~h}$ were $0.21 \pm 0.04,8.4 \pm 0.72$ and $48.2 \pm 14.9 \mathrm{mAU} / \mathrm{ml} / 10^{4}$ cells, respectively, and in cells cultured with $1.25 \mu \mathrm{M}$ sorafenib the levels of DCP secretion at 24,48 and $72 \mathrm{~h}$ were $0.16 \pm 0.03$, $0.29 \pm 0.10$ and $0.66 \pm 0.01 \mathrm{mAU} / \mathrm{ml} / 10^{4}$ cells, respectively $(\mathrm{P}<0.001)$, as illustrated in Fig. 2B. Levels of NX-DCP expression demonstrated a similar trend to DCP. The expression of NX-DCP was generally low, as the highest level was $0.35 \pm 0.09 \mathrm{mAU} / \mathrm{ml} / 10^{4}$ cells at $72 \mathrm{~h}$ in the non-sorafenib cell culture, as demonstrated in Fig. 2C. Prothrombin and VEGF secretion at 24,48 , and $72 \mathrm{~h}$ were all elevated in the sorafenib-treated cell cultures. These expression levels peaked at $48 \mathrm{~h}$ and increased $>2$-fold compared with the non-treated cells $(\mathrm{P}<0.001)$, as illustrated in Fig. $2 \mathrm{D}$ and $\mathrm{E}$.

The same experiments were performed under hypoxic conditions. The levels of cell proliferation decreased subsequent to sorafenib treatment, but the difference was less compared with normoxic conditions, as demonstrated in Fig. 2F. DCP expression was higher in the sorafenib-treated and non-treated cells compared with the cells under normoxic conditions. The level of DCP in the sorafenib-treated cells was significantly lower compared with the control group and the cells under normoxic conditions $(\mathrm{P}<0.001)$, as illustrated 
A Cell number

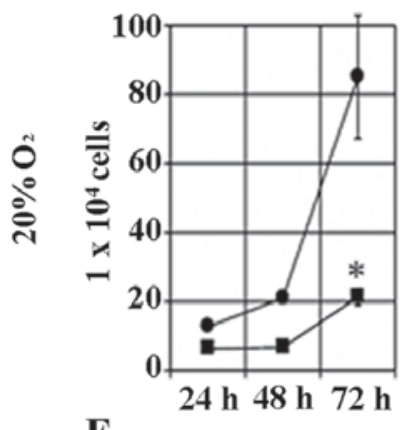

F

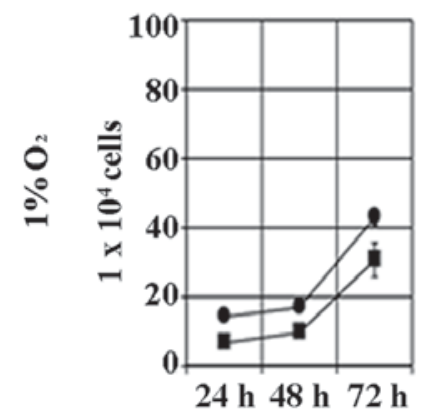

B DCP

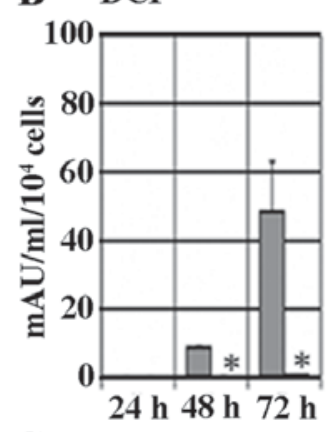

G

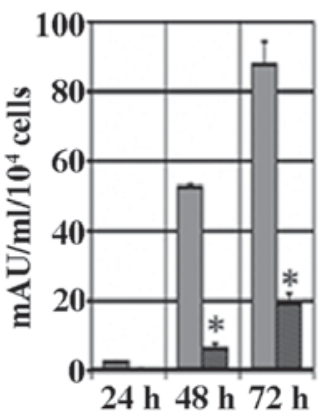

C NX-DCP

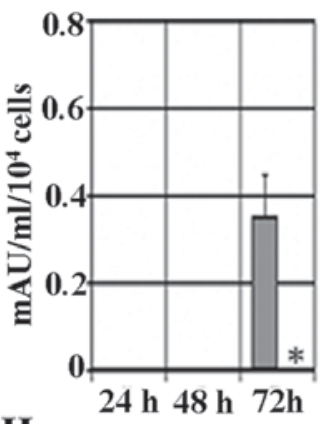

H

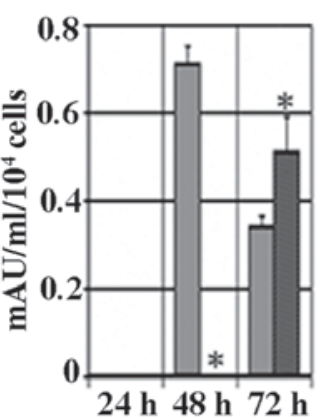

D Prothrombin

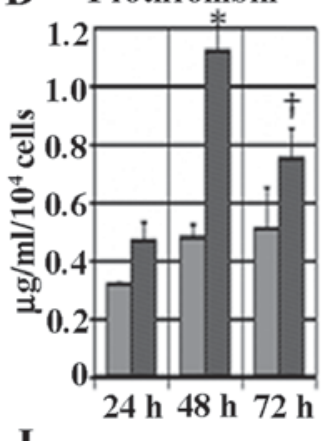

I

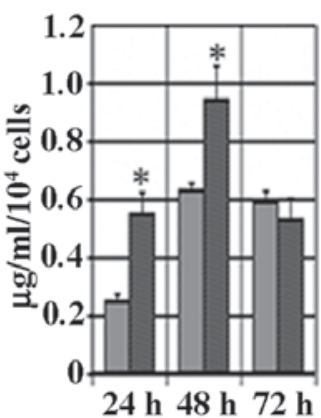

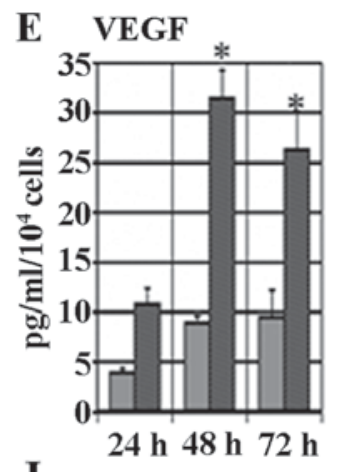

J

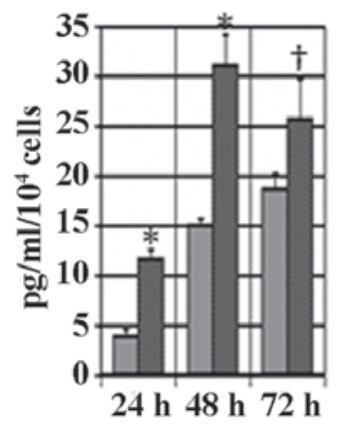

Figure 2. Effect of sorafenib on the proliferation and secretion of DCP, prothrombin, NX-DCP and VEGF. Upper row (A-E), normoxic conditions; lower row (F-J), hypoxic conditions. (A and F) The number of KYN-2 cells cultured with or without $1.25 \mu \mathrm{M}$ sorafenib for 24,48 , or $72 \mathrm{~h}$. The levels of (B and G) DCP; $(\mathrm{C}$ and H) NX-DCP; (D and I) prothrombin; and (E and J) VEGF secreted by KYN-2 cells cultured with medium alone or medium with $1.25 \mu \mathrm{M}$ sorafenib for 24,48 , or $72 \mathrm{~h}$. Data are present as the mean \pm standard deviation from three independent experiments. ${ }^{\dagger} \mathrm{P}<0.01$ and ${ }^{*} \mathrm{P}<0.001$ medium alone vs. medium with sorafenib. DCP, des- $\gamma$-carboxyprothrombin; NX-DCP, des- $\gamma$-carboxyprothrombin with more $\gamma$-carboxyglutamic residues; VEGF, vascular endothelial growth factor; $\mathbf{a}$ /black bar, cells cultured with $1.25 \mu \mathrm{M}$ sorafenib; $\bullet /$ gray bar, cells cultured without $1.25 \mu \mathrm{M}$ sorafenib.

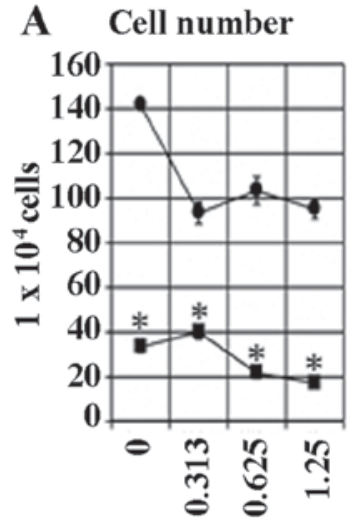

sorafenib $(\mu \mathbf{M})$

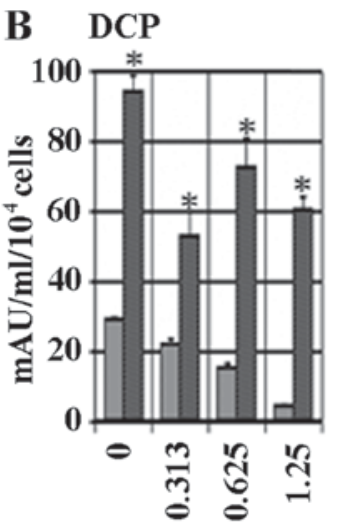

sorafenib $(\mu \mathbf{M})$
C NX-DCP

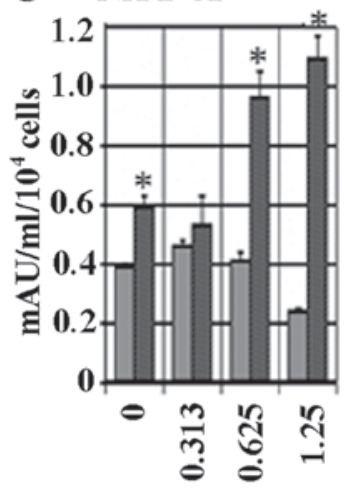

sorafenib $(\mu \mathbf{M})$
D Prothrombin

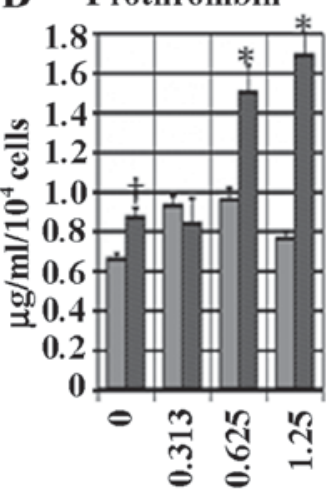

sorafenib $(\mu \mathbf{M})$
E VEGF

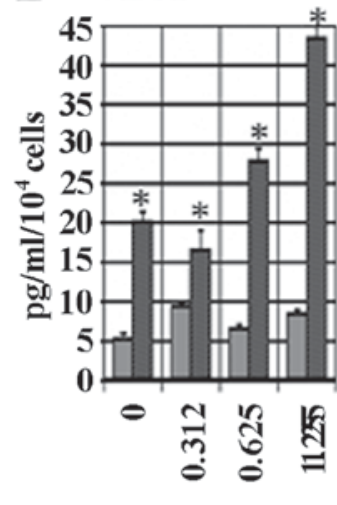

sorafenib $(\mu \mathbf{M})$

Figure 3. Dose-dependent effect of $0.313,0.625$ or $1.25 \mu \mathrm{M}$ sorafenib on the levels of proliferation and secretion of DCP, prothrombin, NX-DCP and VEGF. (A) KYN-2 cells were cultured with medium alone or medium with $0.313,0.625$, or $1.25 \mu \mathrm{M}$ sorafenib in normoxic or hypoxic conditions for $72 \mathrm{~h}$. The (A) cell number and levels of (B) DCP, (C) NX-DCP, (D) prothrombin and (E) VEGF secreted by KYN-2 cells cultured with or without sorafenib in normoxic or hypoxia conditions for $72 \mathrm{~h}$. ${ }^{\dagger} \mathrm{P}<0.01$ and ${ }^{*} \mathrm{P}<0.001$ vs. normoxic condition. $\bullet /$ gray bar, normoxic conditions; $\mathbf{m} /$ black bar, hypoxic conditions; DCP, des- $\gamma$-carboxyprothrombin; NX-DCP, des- $\gamma$-carboxyprothrombin with more $\gamma$-carboxyglutamic residues; VEGF, vascular endothelial growth factor.

in Fig. 2G. NX-DCP expression in sorafenib-treated cells was higher compared with the control at $72 \mathrm{~h}$, as demonstrated in Fig. 2H. The levels of secretion of prothrombin and VEGF under hypoxic conditions were almost the same as under normoxic conditions, as illustrated in Fig. 2I and J. VEGF secretion increased 1.5- to 2-fold compared with non-treated cells under normoxic conditions.

Subsequent to culturing the cells for $72 \mathrm{~h}$ with the addition of sorafenib at a range of concentrations, or without sorafenib, cell proliferation was more significantly suppressed under hypoxic conditions compared with under normoxic conditions. Under these two conditions, sorafenib treatment significantly suppressed cell proliferation $(\mathrm{P}<0.001)$, as demonstrated in Fig. 3A. The level of DCP secretion under normoxic conditions decreased subsequent to sorafenib treatment in a dose-dependent manner, but this effect was enhanced in hypoxic conditions $(\mathrm{P}<0.001)$, as illustrated in Fig. 3B. NX-DCP expression was low compared with DCP, and 
$\mathbf{A}$

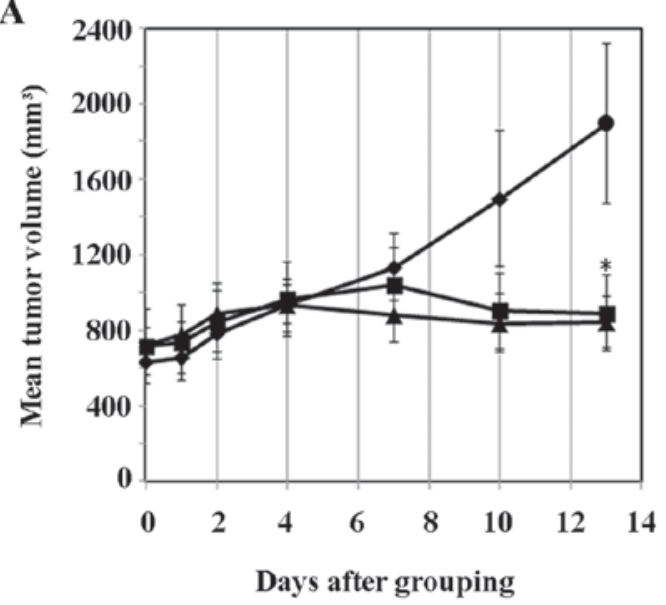

B

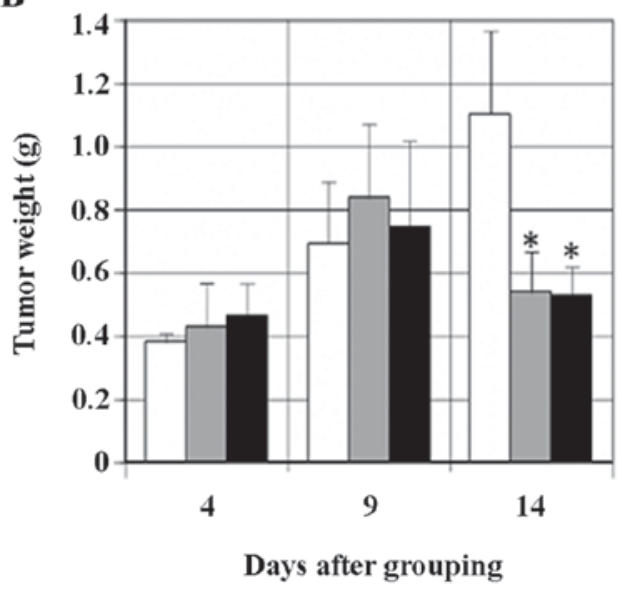

Figure 4. Antitumor effects of sorafenib on tumors developed subsequent to subcutaneous transplantation of KYN-2 cells in nude mice. Mice were sacrificed on day 4, 9, or 14, subsequent to receiving $300 \mu \mathrm{g} / \mathrm{mouse} / \mathrm{day}, 600 \mu \mathrm{g} / \mathrm{mouse} /$ day sorafenib or diluted buffer solution alone. (A) The association between time and estimated tumor volume in mice. (B) Tumor weight of mice that were administered $300 \mu \mathrm{g} / \mathrm{mouse} / \mathrm{day}, 600 \mu \mathrm{g} / \mathrm{mouse} / \mathrm{day}$ sorafenib or diluted buffer. ${ }^{*} \mathrm{P}<0.05$ vs. control. a/gray bar, $300 \mu \mathrm{g} / \mathrm{mouse} /$ day; $\mathbf{\Delta} /$ black bar, $600 \mu \mathrm{g} / \mathrm{mouse} /$ day, $\bullet /$ white bar, diluted buffer only.

A

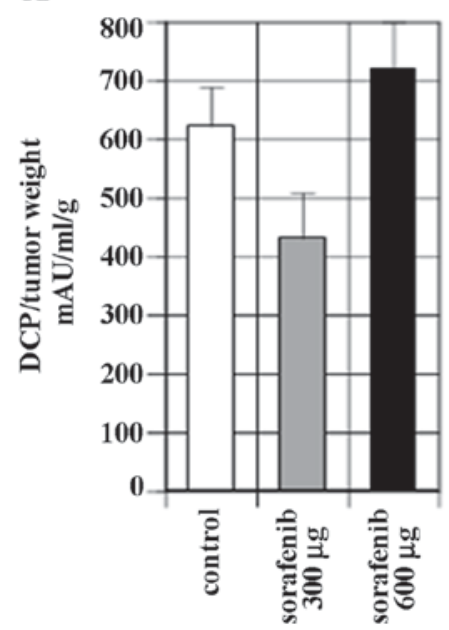

B

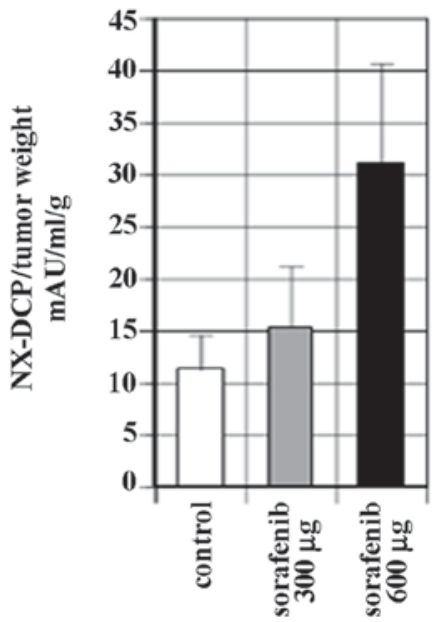

C

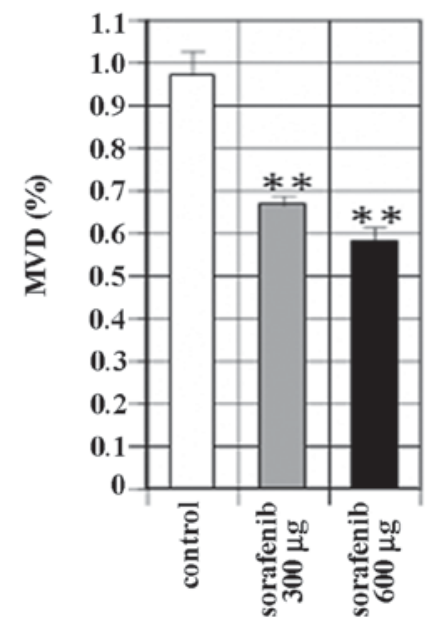

Figure 5. Effect of sorafenib on secretion of DCP and NX-DCP, and MVD of tumors. (A) Serum DCP and (B) NX-DCP levels and (C) MVD of tumor in nude mice that received $300 \mu \mathrm{g} / \mathrm{mouse} /$ day, $600 \mu \mathrm{g} / \mathrm{mouse} /$ day sorafenib or diluted solution alone. ${ }^{* *} \mathrm{P}<0.001 \mathrm{vs}$. control. DCP, des- $\gamma$-carboxyprothrombin; $\mathrm{NX}$-DCP, des- $\gamma$-carboxyprothrombin with more $\gamma$-carboxyglutamic residues; MVD, microvessel density.

tended to decrease subsequent to sorafenib treatment under normoxic conditions. However, NX-DCP levels exhibited an increase under hypoxic conditions $(\mathrm{P}<0.001)$, as demonstrated in Fig. 3C. The secretion of prothrombin and VEGF was also significantly higher under hypoxic conditions in cells treated with high concentrations of sorafenib compared with normoxic conditions $(\mathrm{P}<0.001)$, as illustrated in Fig. 3D and E.

Effects of sorafenib on tumor proliferation and serum DCP and NX-DCP levels in nude mice. The growth of the tumor (tumor volume) was suppressed in sorafenib-treated mice from day 7 compared with the control, and this difference was significant at day $13(\mathrm{P}<0.05)$, as demonstrated in Fig. 4A. Tumor weight also decreased significantly at day 14 in sorafenib-treated mice compared with the control $(\mathrm{P}<0.05)$, as illustrated in Fig. 4B. The tumor volume and weight decreased $\sim 50 \%$ of the control level subsequent to sorafenib treatment, however no difference was observed between the two dose levels, $300 \mu \mathrm{g} / \mathrm{mouse} /$ day or $600 \mu \mathrm{g} / \mathrm{mouse} / \mathrm{day}$, used in the present study. The levels of DCP expression by tumor weight was $622.2 \pm 66.4 \mathrm{mAU} / \mathrm{ml} / \mathrm{g}$ in the control, $430.7 \pm 77.7 \mathrm{mAU} / \mathrm{ml} / \mathrm{g}$ in the sorafenib $300 \mu \mathrm{g} / \mathrm{mouse} /$ day and $763.1 \pm 78.4 \mathrm{mAU} / \mathrm{ml} / \mathrm{g}$ in the sorafenib $600 \mu \mathrm{g} / \mathrm{mouse} /$ day group, as illustrated in Fig. 5A. The levels of NX-DCP expression per unit tumor weight was $11.2 \pm 3.3 \mathrm{mAU} / \mathrm{ml} / \mathrm{g}$ in the control, $15.3 \pm 5.8 \mathrm{mAU} / \mathrm{ml} / \mathrm{g}$ in the sorafenib $300 \mu \mathrm{g} / \mathrm{mouse} /$ day group and $31.1 \pm 9.5 \mathrm{mAU} / \mathrm{ml} / \mathrm{gin}$ the sorafenib $600 \mu \mathrm{g} / \mathrm{mouse} /$ day group, as demonstrated in Fig. 5B. There were no significant differences observed between the levels of expression of DCP or NX-DCP between the sorafenib and control groups.

Immunohistochemical analysis. MVD was significantly reduced to $68.4 \%$ of the control level in the sorafenib $300 \mu \mathrm{g} / \mathrm{mouse} / \mathrm{day}$ group, and $59.4 \%$ of the control level in the sorafenib $600 \mu \mathrm{g} / \mathrm{mouse} /$ day group $(\mathrm{P}<0.001)$. No significant difference in other parameters, such as tumor volume and 
tumor weight, was observed between the two concentrations of sorafenib used, as illustrated in Fig. 5C.

\section{Discussion}

The 10 glutamic acid (Glu) residues of human prothrombin at the N-terminus are typically converted by carboxylase to a Gla domain. DCP is an abnormal prothrombin as all or part of the Gla domain remains as Glu residues. NX-DCP, which is induced in conditions of vitamin $\mathrm{K}$ deficiency, is a protein with a smaller number of Glu residues.

In the present study, the levels of DCP, NX-DCP and prothrombin expression in 13 different cell lines were examined. It was revealed that the expression levels were low in all cell lines except KIM-1 and KYN-2. Comparing the expression levels of DCP, NX-DCP and prothrombin under normoxic or hypoxic conditions, the levels increased under hypoxic conditions in all categories except DCP in the KYN-2 cell lysate. NX-DCP and prothrombin were expressed under hypoxic conditions, but the levels were low compared with levels of DCP. The production of DCP in HCC is hypothesized to be associated with a reduction in the activity of vitamin $\mathrm{K}$ dependent $\gamma$-carboxylase $(27,28)$, excessive production of prothrombin precursors $(29,30)$ and to effects associated with vitamin $\mathrm{K}$ concentration. In the present study, cell proliferation and DCP expression were suppressed under normoxic and hypoxic conditions in $\mathrm{KYN}-2$ cells treated with vitamin $\mathrm{K}$. This suggests that the addition of vitamin $\mathrm{K}$ restored the metabolic pathways to near normal status in the KYN-2 cells where the increased expression of prothrombin lowered the uptake or reduced the activity of vitamin K. In studies using cell lines, vitamin $\mathrm{K}$ treatment was demonstrated to suppress DCP expression, whilst increasing the expression of prothrombin and carboxylase mRNA $(31,32)$. These results suggest that DCP production in HCC may be caused by a reduction in vitamin $\mathrm{K}$ concentration in the microenvironment of the cancer cells. Conversely, vitamin $\mathrm{K}$ derivatives are not reduced in patients with $\mathrm{HCC}$, and one study reported that vitamin $\mathrm{K}$ administration reduced DCP levels (33). However, whilst vitamin $\mathrm{K}$ administration reduced DCP to normal levels in patients exhibiting a high serum level of vitamin $\mathrm{K}$ derivatives, DCP remained abnormal in patients exhibiting low serum levels of vitamin $\mathrm{K}$ derivatives. These data indicate that high levels of DCP are not caused by lowered levels of vitamin $\mathrm{K}$, but by a reduced utilization efficiency caused by a defect in vitamin $\mathrm{K}$ metabolism.

A transitory increase in DCP has been reported in certain patients with HCC subsequent to sorafenib treatment (34). Additionally, progression-free survival in those patients who exhibited an increase in DCP expression levels was longer compared with the patients who exhibited no increase in DCP (17,35). The elevation of DCP subsequent to sorafenib treatment may be a prognostic marker, and this elevation may be caused by tumor cell ischemia. Sorafenib at concentrations of $0.3125-20 \mu \mathrm{M}$ suppressed cell proliferation in a dose-dependent manner in all 13 cell lines used in the present study (data not shown). Similar to the results revealed by Llobet et al (36) and Fernando et al (37), apoptosis was induced in 8 of the cell lines in between 5 to $50 \%$ of the cells, however the induction of autocrine cell proliferation by DCP or activation of hepatocyte growth factor receptor was not observed such as the report of Suzuki et al (38) and Gao and Vande Woude (39).

In the in vivo experiment of the present study, tumor volume and weight, and blood vessel density were suppressed in mice receiving $600 \mu \mathrm{g} / \mathrm{mouse} /$ day sorafenib, compared with the control group. The present study hypothesizes that the inhibitory effect of sorafenib on neovascularization is responsible for the suppression of tumor proliferation. Also, NX-DCP secretion per unit weight increased in the sorafenib-treated mice, which may be an additional mechanism of creating a hypoxic environment through the inhibition of neovascularization.

The levels of DCP and NX-DCP secretion were significantly decreased in sorafenib treated cell cultures compared with the non-treated controls, whereas levels of prothrombin and VEGF expression were increased. However, under normoxic conditions levels of NX-DCP expression increased at $72 \mathrm{~h}$ subsequent to sorafenib treatment. The DCP values increased under hypoxic conditions compared with normoxic conditions, but decreased significantly in the cells cultured with sorafenib. With regard to the increase in levels of DCP expression under hypoxic conditions, as reported by Murata et al (40), hypoxic conditions induce epithelial to fibroblastoid conversion and epithelial mesenchymal transition, which may inhibit vitamin K uptake and stimulate DCP production. Conversely, levels of NX-DCP secretion exhibited a different trend compared with DCP in the sorafenib-treated cells under hypoxic conditions. At $48 \mathrm{~h}$, sorafenib suppressed NX-DCP secretion, but at $72 \mathrm{~h}$ an increase in NX-DCP was observed. In our previous study of resected HCC tissues, NX-DCP originated from non-tumorous cells in the background, whilst expression within the cancerous area was limited (10). With regard to the production of NX-DCP in $\mathrm{HCC}$, it is possible that the direct effects of sorafenib and blood vessel ischemia may be responsible for the increase in levels of serum NX-DCP. However, NX-DCP from non-cancerous hepatocytes may also be present in the sera to varying degrees, so an accurate assessment of this effect may prove difficult.

As a mechanism for the increase in DCP observed in patients with HCC subsequent to sorafenib treatment, the present study suggests that the suppression of neovascularization by sorafenib promotes blood vessel ischemia, producing hypoxic conditions whereby vitamin $\mathrm{K}$ uptake and utilization efficiency is reduced. In these circumstances it is likely that the degree of the increase in serum DCP will be determined according to a balance between the direct suppression of DCP by sorafenib and the increase in DCP secretion due to ischemia.

\section{Acknowledgements}

The authors would like to thank Ms. Akemi Fujiyoshi for her assistance in the present study.

\section{References}

1. Liu L, Cao Y, Chen C, Zhang X, McNabola A, Wilkie D, Wilhelm S, Lynch $M$ and Carter C: Sorafenib blocks the RAF/MEK/ERK pathway, inhibits tumor angiogenesis, and induces tumor cell apoptosis in hepatocellular carcinoma model PLC/PRF/5. Cancer Res 66: 11851-11858, 2006.

2. Llovet JM, Ricci S, Mazzaferro V, Hilgard P, Gane E, Blanc JF, de Oliveira AC, Santoro A, Raoul JL, Forner A, et al: Sorafenib in advanced hepatocellular carcinoma. N Engl J Med 359: 378-390, 2008. 
3. Escudier B, Eisen T, Stanler WM, Szczylik C, Oudard S, Staehler M, Negrier S, Chevreau C, Desai AA, Rolland F, et al: Sorafenib for treatment of renal cell carcinoma: Final efficacy and safety results of the phase III treatment approaches in renal cancer global evaluation trial. J Clin Oncol 27: 3312-3318, 2009.

4. Carlomagno F, Anaganti S, Guida T, Salvatore G, Troncone G, Wilhelm SM and Santoro M: BAY 43-9006 inhibition of oncogenic RET mutants. J Natl Cancer Inst 98: 326-334, 2006.

5. Wilhelm SM, Carter C, Tang L, Wilkie D, McNabola A, Rong H, Chen C, Zhang X, Vincent P, McHugh M, et al: BAY 43-9006 exhibits broad spectrum oral antitumor activity and targets the RAF/MEK/ERK pathway and receptor tyrosine kinases involved in tumor progression and angiogenesis. Cancer Res 64 7099-7109, 2004.

6. Liebman HA, Furie BC, Tong MJ, Blanchard RA, Lo KJ, Lee SD, Coleman MS and Furie B: Des-gamma-carboxy (abnormal) prothrombin as a serum marker of primary hepatocellular carcinoma. N Engl J Med 310: 1427-1431, 1984.

7. Sakon M, Monden M, Gotoh M, Kanai T, Umeshita K, Nakano Y, Mori T, Sakurai M and Wakasa K: Relationship between pathologic prognostic factors and abnormal levels of des-gamma-carboxy prothrombin and alpha-fetoprotein in hepatocellular carcinoma. Am J Surg 163: 251-256, 1992.

8. Suehiro T, Sugimachi K, Matsumata T, Itasaka H, Taketomi A and Maeda T: Protein induced by vitamin K absence or antagonist II as a prognostic marker in hepatocellular carcinoma. Comparison with alpha-fetoprotein. Cancer 73: 2464-2471, 1994.

9. Sakamoto N: NX-PVKA assay, a conventional but refined prognostic biomarker for hepatocellular carcinoma. J Gastroentero Hepatol 28: 755-756, 2013.

10. Sumi A, Akiba J, Ogasawara S, Nakayama M, Nomura Y, Yasumoto M, Sanada S, Nakashima O, Abe T and Yano $\mathrm{H}$ : Des- $\gamma$-carboxyprothrombin (DCP) and NX-DCP expressions and their relationship with clinicopathological features in hepatocellular carcinoma. PLoS One 10: e0118452, 2015.

11. Kim BK, Ahn SH, Seong JS, Park JY, Kim DY, Kim JK, Lee DY, Lee $\mathrm{KH}$ and Han KH: Early $\alpha$-fetoprotein response as a predictor for clinical outcome after localized concurrent chemoradiotherapy for advanced hepatocellular carcinoma. Liver Int 31: 369-376, 2011.

12. Johnson PJ: The role of serum alpha-fetoprotein estimation in the diagnosis and management of hepatocellular carcinoma. Clin Liver Dis 5: 145-159, 2001.

13. Zhou L, Liu J and Luo F: Serum tumor markers for detection of hepatocellular carcinoma. World J Gastroenterol 12: 1175-1181, 2006.

14. Malaguarnera G, Giordano M, Paladina I, Berretta M, Cappellani A and Malaguarnera M: Serum markers of hepatocellular carcinoma. Dig Dis Sci 55: 2744-2755, 2010.

15. Kuzuya T, Asahina Y, Tsuchiya K, Tanaka K, Suzuki Y, Hoshioka T, Tamaki S, Kato T, Yasui Y, Hosokawa T, et al: Early decrease in $\alpha$-fetoprotein, but not des- $\gamma$-carboxy prothrombin, predicts sorafenib efficacy in patients with advanced hepatocellular carcinoma. Oncology 81: 251-258, 2011.

16. Nakazawa T, Hidaka H, Shibuya A and Koizumi W: Rapid regression of advanced hepatocellular carcinoma associated with elevation of des-gamma-carboxy prothrombin after short-term treatment with sorafenib-a report of two cases. Case Rep Oncol 3: 298-303, 2010.

17. Ueshima K,KudoM,Takita M,Nagai T, TatsumiC,Ueda T,KitaS, Ishikawa E, Yada N, Inoue T, et al: Des- $\gamma$-carboxyprothrombin may be a promising biomarker to determine the therapeutic efficacy of sorafenib for hepatocellular carcinoma. Dig Dis 29: 321-325, 2011.

18. Murakami T: Establishment and characterization of human hepatoma cell line (KIM-1). Acta Hepatol Jpn 25: 532-539, 1984.

19. Yano H, Kojiro M and Nakashima T: A new human hepatocellular carcinoma cell line (KYN-1) with a transformation to adenocarcinoma. In Vitro Cell Dev Biol 22: 637-646, 1986

20. Yano H, Maruiwa M, Murakami T, Fukuda K, Ito Y, Sugihara S and Kojiro M: A new human pleomorphic hepatocellular carcinoma cell line, KYN-2. Acta Pathol Jpn 38: 953-966, 1988.

21. Murakami T, Maruiwa M, Fukuda K, Kojiro M, Tanaka M and Tanikawa K: Establishment and characterization of a new human hepatoma cell line (KYN-3) derived from the ascites of the hepatoma paitient. Proceedings of the Japanese Cancer Association. Jpn J Cancer Res: 292, 1988.
22. Yano H, Iemura A, Fukuda K, Mizoguchi A, Haramaki M and Kojiro M: Establishment of two distinct human hepatocellular carcinoma cell lines from a single nodule showing clonal dedifferentiation of cancer cells. Hepatology 18: 320-327, 1993.

23. Haramaki M, Yano H, Iemura A, Momosaki S, Ogasawara S, Inoue M, Yamaguchi R, Kusaba A, Utsunomiya I and Kojiro M: A new human hepatocellular carcinoma cell line (HAK-2) forms various structures in collagen gel matrices. Hum Cell 10: 183-192, 1997.

24. Utsunomiya I, Iemura A, Yano H, Akiba J and Kojiro M Establishment and characterization of a new human hepatocellular carcinoma cell line, HAK-3, and its response to growth factors. Int J Oncol 15: 669-675, 1999.

25. Murakami T, Yano H, Maruiwa M, Sugihara S and Kojiro M: Establishment and characterization of a human combined hepatocholangiocarcinoma cell line and its heterologous transplantation in nude mice. Hepatology 7: 551-556, 1987.

26. Yano H, Iemura A, Haramaki M, Momosaki S, Ogasawara S, Higaki $\mathrm{K}$ and Kojiro M: A human combined hepatocellular and cholangiocarcinoma cell line $(\mathrm{KMCH}-2)$ that shows the features of hepatocellular carcinoma or cholangiocarcinoma under different growth conditions. J Hepatol 24: 413-422, 1996.

27. Shah DV, Engelke JA and Suttie JW: Abnormal prothrombin in the plasma of rats carrying hepatic tumors. Blood 69: 850-854, 1987.

28. Shah DV, Zhang P, Engelke JA, Bach AU and Suttie JW: Vitamin K-dependent carboxylase activity, prothrombin mRNA, and prothrombin production in two cultured rat hepatoma cell lines. Thromb Res 70: 365-373, 1993.

29. OnoM,OhtaH,Ohhira M,SekiyaCand NamikiM:Measurement of immunoreactive prothrombin, des-gamma-carboxy prothrombin, and vitamin $\mathrm{K}$ in human liver tissues: Overproduction of immunoreactive prothrombin in hepatocellular carcinoma. Am J Gastroenterol 85: 1149-1154, 1990.

30. Yamagata $H$, Nakanishi T, Furukawa M, Okuda $H$ and Obata $H$ : Levels of vitamin K, immunoreactive prothrombin, des-gammacarboxy prothrombin and gamma-glutamyl carboxylase activity in hepatocellular carcinoma tissue. J Gastroenterol Hepatol 10: 8-13, 1995 .

31. Wang Z, Wang M, Finn F and Carr BI: The growth inhibitory effects of vitamins $\mathrm{K}$ and their actions on gene expression. Hepatology 22: 876-882, 1995.

32. Okuda $\mathrm{H}$, Obata $\mathrm{H}$, Nakanishi $T$, Furukawa $\mathrm{R}$ and Hashimoto $\mathrm{E}$ : Production of abnormal prothrombin (des-gamma-carboxy prothrombin) by hepatocellular carcinoma. A clinical and experimental study. J Hepatol 4: 357-363, 1987.

33. Sakon M, Monden M, Gotoh M, Kobayashi K, Kanai T, Umeshita K, Endoh W and Mori T: The effects of vitamin K on the generation of des-gamma-carboxy prothrombin (PIVKA-II) in patients with hepatocellular carcinoma. Am J Gastroenterol 86 339-345, 1991.

34. Kuzuya T, Tsuchiya K, Tanaka K, Suzuki Y, Hoshioka T, Tamaki S, Kato T, Yasui Y, Tanaka T, Hosokawa T, et al: Significance of PIVKA-II in sorafenib therapy for advanced hepatocellular carcinoma. Kanzo 51: 403-404, 2010.

35. Ueshima K and Kudo M: PIVKA-II is a predictive marker in the treatment response of sorafenib to hepatocellular carcinoma. Kanzo 51: 681-683, 2010

36. Llobet D, Eritja N, Yeramian A, Pallares J, Sorolla A, Domingo M, Santacana M, Gonzalez-Tallada FJ, Matias-Guiu X and Dolcet X: The multikinase inhibitor Sorafenib induces apoptosis and sensitises endometrial cancer cells to TRAIL by different mechanisms. Eur J Cancer 46: 836-850, 2010.

37. Fernando J, Sancho P, Fernández-Rodriguez CM, Lledó JL, Caja L, Campbell JS, Fausto N and Fabregat I: Sorafenib sensitizes hepatocellular carcinoma cells to physiological apoptotic stimuli. J Cell Physio 227: 1319-1325, 2012.

38. Suzuki M, Shiraha H, Fujikawa T, Takaoka N, Ueda N, Nakanishi Y, Koike K, Takaki A and Shiratori Y: Des-gammacarboxy prothrombin is a potential autologous growth factor for hepatocellular carcinoma. J Biol Chem 280: 6409-6415, 2005.

39. Gao CF and Vande Woude GF: HGF/SF-Met signaling in tumor progression. Cell Res 15: 49-51, 2005.

40. Murata K, Suzuki H, Okano H, Oyamada T, Yasuda Y and Sakamoto A: Hypoxia-induced des-gamma-carboxy prothrombin production in hepatocellular carcinoma. Int J Oncol 36: 161-170, 2010. 